\title{
Detection of Aflatoxins from Malt Barley Under Storage Conditions in Central Ethiopia
}

\author{
By Getnet Muche Abebele* Alemu Ayele Zerihun \\ Ethiopian Institute of Agricultural Research, Kulumsa Agricultural Research Center, P.O. Box. 489, Asella, \\ Ethiopia
}

\begin{abstract}
Aflatoxins are non avoidable highly poisonous and carcinogenic auxiliary metabolite produced by some molds belonging to Aspergillus genera on range of agricultural products including malt barley. This study was conducted with the aim to examine total aflatoxin (AFT) concentration in malt barley samples. A total of eighty seven malt barley samples collected from farmers' stores and seed enterprises' of Amhara and Oromia regions were employed for aflatoxin analysis through an ELISA test. Of these, 30 (34.48\%) were positive whereas the remaining 57 $(54.03 \%)$ were negative. The total aflatoxin levels in the positive samples layover in a range between $0.0005 \mu \mathrm{gkg}-$ ${ }^{1}$ and $0.04 \mu \mathrm{gkg}^{-1}$. The existing results undoubtedly revealed insignificant contamination of malt barley samples in Ethiopia, suggesting that concentrations were low enough and ensure compliance with the Food and Agricultural Organization of the United Nations (FAO) $20 \mathrm{ugkg}^{-1}$, World Health Organization (WHO) $15 \mu \mathrm{gkg}^{-1}$ and European Union (EU) 4-15ugkg-1 admitted levels depending on the raw material use of cereals. Fortunately, the result of this study may not lead to infer the urgent need to apply control measures against aflatoxigenic fungi and associated aflatoxins that could result adverse effects. The major factors for less contamination of malt barley by aflatoxin were expected to be pre- and post-harvest environmental factors, mechanized harvesting and proper management practices like drying before storage. Although the present status of aflatoxins is remarkably at lower concentrations, regular and accurate cereal quality testing is critical to reduce the risk of severe health problems as well as international trade repercussions.
\end{abstract}

Keywords: Adverse effect, Auxiliary metabolite, Contamination, ELISA, Molds.

DOI: $10.7176 / \mathrm{JBAH} / 10-15-01$

Publication date:August $31^{\text {st }} 2020$

\section{Introduction}

Barley (Hordeum vulgare L.) is one of the world's most early domesticated and widely adapted crop species, being cultivated in the Nile River Valley of Egypt at least 17,000 years ago (Wendorf, 1979; Purugganan, 2009). To date, barley is the fourth most important cereal crop globally, produced in more than 100 countries for the purpose of animal feed and alcoholic beverages. Barley is grown on 55 million ha worldwide with a total production of 140 million metric tons (Zhou, 2010), with developed countries taking the largest proportion both in production and consumption (FAOSTAT; USDA, 2010).

Ethiopia is the second principal barley producer in Africa, after Morocco, sharing about 25 percent of the total barley production in the continent (FAO, 2014). According to CSA (2018), 951,993.15 ha of land was cultivated for barley and provided 20,529,963.72 quintals of grain harvest. However, Ethiopia produces mostly food barley, with its share estimated to be 90 percent (Alemu et al., 2014), and remains significantly deficient in malt barley. South Eastern, Central and Northern highlands of Ethiopia particularly areas like Arsi, West Arsi, Bale, North Shewa and North Gondar zones have potentials for producing malt barley for commercial purpose that able to meet the growing demand by brewing malt factories (Tadesse and Derso, 2019).

Barley production is constrained by several factors like socio-economic, abiotic factors and biotic factors mainly pests and diseases (Getachew et al 2016; Brown et al 2011 ;). Among the biotic constraints different species of molds from genera such as, Alternaria, Aspergillus, Cladosporium, Fusarium, Pencillium and Rhizopus have all been reported to deteriorate quality of malt. The contamination may occur both in the field and during storage. Under favorable conditions of high moisture and humidity those groups of fungi have the potential to produce unwanted secondary metabolites known as mycotoxins that can persist through the brewing process and produce adverse effects. The most known contaminants of malt barley are Aspergilus species which are common saprophytic fungi found in seeds, malt and wort (Cairns et al., 2018; Anne et al 2005). Aspergillus are diverse in number as well as in their range of toxicities responsible for acute toxicity, chronic toxicity, carcinogenicity, teratogenicity, genotoxicity, impair growth and immunotoxicity on humans and, and immunosuppressive on animals (IARC. 2002). Almost 50 species of Aspergilus have been identified as responsible of producing toxic mycotoxins (Rizzi et al., 2003, Cole et al., 1982).

Aflatoxins are considered unavoidable contaminants of food and feed, even where good manufacturing practices have been followed hence considered as most dangerous in contaminating human food and animal feed (Robens and Richard,1992; Wild C \& Gong Y. 2010; Frisvad et al ., 2004). For instance according to Williams et al. (2004) about 4.5 billion of the world's population is exposed to aflatoxins because they are also everywhere. 
Malt barley, sorghum and other cereals that can be used as major raw materials for brewing process are known to be at risk contaminated by aflatoxins (Karolina, Sylvie, Renata, and Zdenek, 2011). Taking in to consideration the health risk they cause to consumers, different international organizations put permissible level of $20 \mathrm{ug} / \mathrm{kg}$ (FDA, 2011), 15ug/kg FAO and WHO (Codex, 2001) while the European union(EU) placed a more stringent level of 4 $\mathrm{ug} / \mathrm{kg}$ for total aflatoxins in commodities destined for human consumption( Moss, 2002). This was found to affect international trade that inturn limit economies of several developing countries including Ethiopia(Nigussie et al.,2018; Alemayehu et al., 2012; Dimanchine, 2001).

There are attempts in different countries and organizations to identify and minimize the harms associated with moulds and their secondary metabolite aflatoxins contamination of malt barley (FAO, 1997). Previous study reports on mycotoxins in the European malting and brewing industries, indicating aflatoxins (AFs), as one of the most important mycotoxins in the barley beer chain (Dupire 2003; Melotte, 2004 and Boivin, 2005). Similarly earlier studies on aflatoxin contamination of barley and malt barley sourced beer indicated the detection of different levels of aflatoxin (Habtamu et al. 2001; Nigussie et al. 2018) in Ethiopia. However, research based information's regarding the fate of aflatoxins and malt barely is still highly limited. Thus, this study was carried out to assess the status of aflatoxins in stored malt barley in major producing areas of central Ethiopia.

\section{Materials and Methods}

\subsection{Description of study area}

A total of ten districts within four major malt barley growing zones namely Arsi, west Arsi and Bale zones from Oromia regional state and North Shewa from Amhara regional state were purposively selected since they share large volume of malt barley production in Ethiopia (Addisu A. 2017). Detail geographical, latitudinal, altitudinal and longitudinal descriptions of the study areas are provided below in Table 1.

Surveyed districts in Bale zone have the mean annual temperature $22.8^{\circ} \mathrm{C}$ and $14.4{ }^{\circ} \mathrm{C}$ and rainfall of $628 \mathrm{~mm}$ and $930 \mathrm{~mm}$ for Goba and Sinana districts respectively. The economy of the stated districts as well as zone as a whole is dominated by agriculture. The farming system is mainly characterized by producing annual plants like coffee and cereals mainly wheat and malt barley in to two seasons, belg season and meher growing seasons.

The districts from Arsi zone have a mean annual temperature of $13.0^{\circ} \mathrm{C}$ and $15.1^{\circ} \mathrm{C}$ and rainfall $1033 \mathrm{~mm}$ and $1147 \mathrm{~mm}$ for Lemmu-bilbilo and Tiyo respectively. Generally the districts receive abundant and well distributed rainfall both in amount as well as season make is conducive to produce different type's crops and vegetation.

The survey districts from North Shewa of Amhara region have a mean annual temperature of $15.1^{\circ} \mathrm{C}, 14.4^{\circ} \mathrm{C}$ and $14.7^{\circ} \mathrm{C}$ and 989,964 and $926 \mathrm{~mm}$ rainfall for Tarmaber, Debre Berhan and Angolela respectively. Mixed farming systems composed of annual crops, perennial crops, trees and livestock productions are common among all the districts.

Study districts from West Arsi zone have a mean annual temperature of $25.5,26$, and $20{ }^{\circ} \mathrm{C}$ and rainfall of 3917, 1616 and $1400 \mathrm{~mm}$ for Kofele, Adaba and Dodola respectively. These districts have two types of climates prevailing tropical savanna and moderateype. The pattern of rain fall is usually bimodal and its distribution is mostly even. Agricultural production of the districts is mixed cropping system with livestock production and cereal crops and mainly wheat and malt barley.

Table 1. Detail geographical and coordination descriptions of the study areas.

\begin{tabular}{|c|c|c|c|c|c|}
\hline Region & Zones & Districts within zone & Altitude & Latitude(N) & Longitude(E) \\
\hline & & Lemu-bilbilo & & & \\
\hline & & Digelu-tijo & & & \\
\hline & Arsi & Tiyo & 2210-3089 & 0724384-0800802 & 03907248-03914941 \\
\hline & & Goba & & & \\
\hline & Bale & Sinana & $2379-2703$ & 0700671-0707103 & 03958186-04018748 \\
\hline & & Dodola & & & \\
\hline & & Adaba & & & \\
\hline \multirow[t]{3}{*}{ Oromia } & West Arsi & Kofele & $2415-3038$ & 0658591-0705145 & 03845715-03930529 \\
\hline & & Tarmaber & & & \\
\hline & & D/ Berhan & & & \\
\hline Amhara & North Shewa & Angolela & 2674-2932 & 0927477-09410455 & 03923138-03945782 \\
\hline
\end{tabular}

\subsection{Sample Collection}

A total of eighty seven malt barley samples grown in 2016 were randomly collected from farmers' stores and seed stores of enterprises in the abovementioned surveyed areas. Samples were properly labeled with the name of the location and sample collection date. During the survey, data were also collected on the latitude, longitude and altitude of the sampled areas (Table1). 


\subsection{Aflatoxin analysis}

Total aflatoxin content of samples was determined using enzyme linked immunosorbent assay (ELISA) as outlined below.

\subsubsection{Sample preparation}

About 87 grain samples of malt barely obtained from farmers' stores and the local markets of selected locations of eleven districts from two regions Amhara and Oromia were used for determination of total aflatoxin concentrations. About $400 \mathrm{~g}$ of each representative sample was ground to a fine instant coffee $(50 \%$ passes through a 20 mesh screen) via (ThomasWILEY, LABORATORY MILL, and Model 4. ARTHUR H. THOMAS Company PHILADELPHIA, PA., U.S.A.). Subsamples of $20 \mathrm{~g}$ each were then extracted in $100 \mathrm{ml}$ of $80 \%$ methanol by stirring on a magnetic stirrer (Variomag, Poly 15, Thermo Scientific, Thermo Electron LED GmbH, Langenselbold, Germany) for 7 minutes. The obtained suspension was filtered through a Whatman No. 1 filter paper (Whatman International Ltd., Maidstone, UK) and $15 \mathrm{ml}$ of distilled water and $0.25 \mathrm{ml}$ of Tween 20 were added to $5 \mathrm{ml}$ of the filtered solution. The resulting suspension was then vortexed for $30 \mathrm{~s}$.

\subsubsection{Aflatoxin analysis by ELISA}

Aflatoxin analysis was carried out using ELISA kits (Sigma-Aldrich ${ }^{\circledR}$ Total Aflatoxin ELISA kit Low Matrix (Qual) solid phase direct competitive enzyme immunoassay according to the manufacturer's recommendation. All the reagents were brought to room temperature before use. One hundred microliters of the standard solutions and prepared samples were transferred to each well of the micro-titer plate in duplicate and dispensed on 200ul sample diluent and mix by priming pipettor. a dilut. Then 100ul of enzyme conjugate and $50 \mathrm{ul}$ of the antibody solution were added to each well, and the contents of the wells were mixed gently by shaking the plate manually. After incubation for $30 \mathrm{~min}$ at room temperature $\left(25^{\circ} \mathrm{C}\right)$ in the dark, the wells were emptied by inverting the microwell holder upside down and tapping it vigorously against absorbent paper. This was followed by washing the wells with $250 \mathrm{ml}$ washing buffer two times. One hundred $\mathrm{ml}$ of substrate (Chromogen) was added to each well, mixed gently by shaking the plate manually, and the reaction was stopped by adding $100 \mathrm{ml}$ of stop solution into each well after 15 min incubation at room temperature in the dark. Finally, absorbance of each well was measured by ELISA reader (Multiscan Ex microplate photometer; Thermo Electron Corporation, Vantac, Finland) at $650 \mathrm{~nm}$ within 30 min after addition of stop solution.

\section{Results and Discussion}

\subsection{Determination of total aflatoxin concentration by ELISA}

From 87 samples examined for total aflatoxin concentration, 30 samples were positive (Table 2). The concentration of aflatoxins in the positive samples ranged from 0.0005 to $0.04 \mathrm{ugkg}_{-}{ }^{1}$ revealing low contamination of malting barley by aflatoxin compared with the maximum tolerable level by the FAO/WHO $\left(15 \mathrm{ugkg}^{-1}\right)$ and that of EU (4 ugkg $\left.^{-1}\right)$.

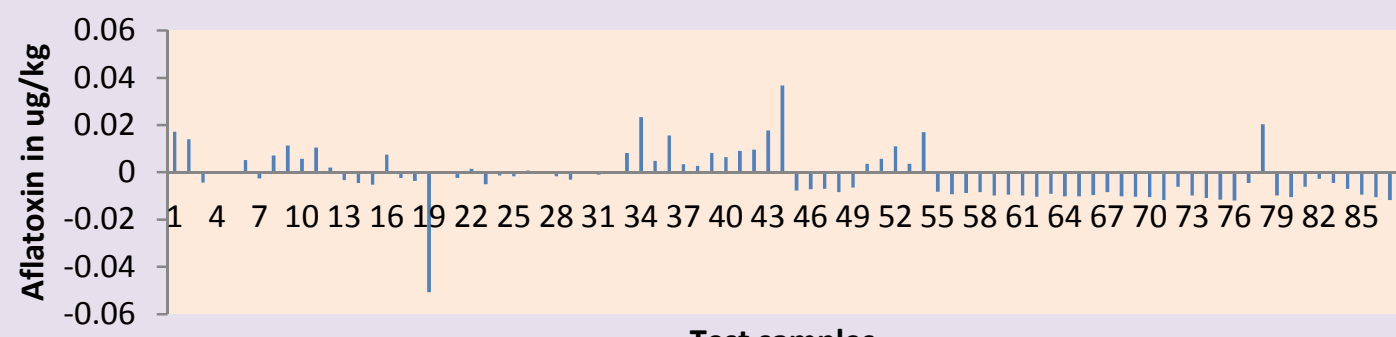

Test samples

Figure 1. Detction of total aflatoxins from malting barley collected from major growing areas of Ethiopia

Table 2. Total aflatoxin contamination status of analyzed malting barley samples from four zones.

\begin{tabular}{lrlllr} 
& Number & of & Positive & Negative & Positive \\
Zome & samples analyzed & samples (\%) & Samples & Exceeding \\
Arsi & 37 & $8(21.62 \%)$ & $29(78.37 \%)$ & & 0 \\
Bale & 21 & $5(23.81 \%)$ & $16(76.19 \%)$ & & 0 \\
North Shoa & 22 & $13(59.09 \%)$ & $9(40.9 \%)$ & & 0 \\
West Arsi & 7 & $4(57.14 \%)$ & $3(42.85 \%)$ & & 0 \\
Total & 87 & $30(34.48 \%)$ & $57(54.03 \%)$ & 0 & \\
\hline
\end{tabular}

Thirty seven samples were tested for total aflatoxin concentration from districts of Arsi zone. Of this, eight samples showed detectable aflatoxins concentrations ranging between $0.025 \mathrm{ugkg}^{-1}$ and $0.002 \mathrm{ugkg}^{-1} \mathrm{but}_{\text {all the }}$ positive samples were below the international minimum permissible levels. While most of the test samples $29(78.37 \%$ ) were aflatoxin negative or below level of detection (Table 2 and Figure 1). From districts of Bale zone, 
a total of 21 malting barley samples were tested for total aflatoxin concentration and $5(23.81 \%)$ samples were positive. Aflatoxin concentration in the positive samples taken from farmers' stores within the district varied from $0.017 \mathrm{ugkg}^{-1}$ to $0.0035 \mathrm{ugkg}^{-1}$. On the other hand, $16(76.19 \%)$ were aflatoxin negative.

Relatively, fewer grain samples were collected and analysed from districts of West Arsi zone, and lowest rate of aflatoxin contamination ranging from $0.017 \mathrm{ugkg}^{-1}$ to $0.00046 \mathrm{ugkg}^{-1}$ were obtained from this zone. As contrasted to districts of Arsi, Bale and West Arsi zone, there was a superior malt barley contamination by total aflatoxin in North Shoa zone where out of 22 samples, $59.09 \%$ were contaminated with total aflatoxin ranging from $0.036 \mathrm{ugkg}^{1-}$ to $0.00077 \mathrm{ugkg}^{1-}$ while the rest $40.9 \%$ samples were aflanegative.

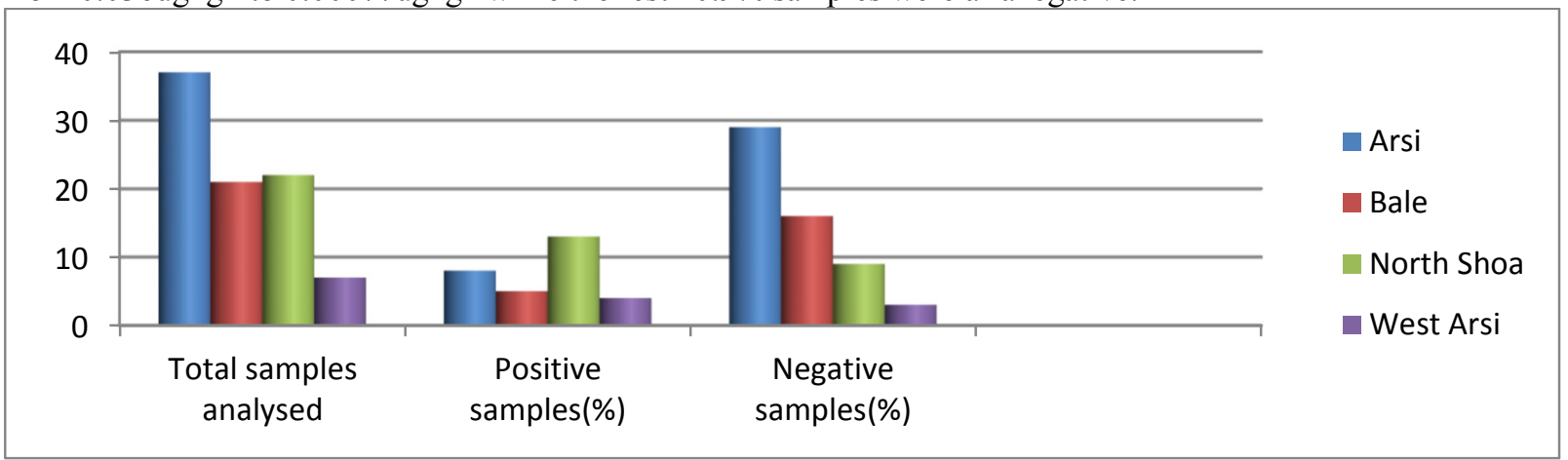

Figure 2. Comparative total aflatoxin contamination of malting barley samples from four zones

Addisu A. (2017) reported total aflatoxin concentration of $5.3 \mathrm{ugkg}^{1-}, 1.9 \mathrm{ugkg}^{1}$ and $6.72 \mathrm{ugkg}^{1-}$ in traditionally producers samples collected from Debre Markos, Finoteselam and Injibara North western Ethiopia respectively. The same author has described total aflatoxin contamination in industrially produced barley malt and obtained $1.22 \mathrm{ugkgs}^{1-}$ and $1.69 \mathrm{ugkg}^{1-}$ respectively. In another study, Afework N. et al. (2018) indicated total aflatoxin concentration from malt barley used twelve alcoholic beer brands working in Ethiopia of which $91.66 \%$ were positive with a range of aflatoxin concentration 1.23 to $12.47 \mathrm{ug} / \mathrm{l}$.

Results from along all the study malt barley growing zones indicated lower aflatoxin pollution of malt barley grain samples. This lower level of aflatoxin concentration might be because of unfavorable weather conditions to occur grain molds which intern result aflatoxins. Although, the number and frequency of aflatoxin studies of food and feed grains at large and malt barley grains in particular are too few; the aflatoxin concentration discovered in the existing study is generally much lower than those previous reports from Ethiopia. Furthermore, a study conducted in Argentina by Gonzalez et al. (2011) reported 19-44.52ugkg ${ }^{-1}$ of AFB1 in a brewer's grain samples. A study by María et al. (2010) revealed that malt barley samples from Spain have been contaminated to the extent of $0.15-0.34 \mathrm{ugkg}^{-1}$ aflatoxin.

The aflatoxin safety regulations and maximum permissible limits are strictly legalized in developed Western countries (Shephard, 2003) although factors inducing fungal deterioration and aflatoxin production are much more frequent in developing tropical countries (Heather S. et al. 2006). The European Union set a maximum tolerance limit for total aflatoxins to $4 \mathrm{ugkg}^{-1}$ while certain developing countries and the US limit total aflatoxins to no more than $20 \mathrm{ugkg}^{-1}$ in food stuffs aimed directly for human consumption or be used as raw material for food preparation (FAO, 2004)

\section{Conclusion}

The finding of this study was compared to the European Legislation, FAO and FDA for total aflatoxin contamination however; none of the samples were showed above the tolerable limit. Although, the result of the present finding has shown lesser aflatoxin pollution extensive surveys of malt barley grain, for aflatoxin pollution should be further continued so as to appraise their safety as well as the contribution of beer to aflatoxin human exposure and to develop and maintain precautionary actions.

\section{References}

Alemu, D., Kelemu, K. and Lakew B. 2014. Trends and prospects of malt barley value chains in Ethiopia. Addis Ababa, Ethiopia.

Anne V., Tadhg O.,'Sullivan and Douwe van Sinderen. 2005. Enhancing the Microbiological Stability of Malt and Beer - A Review. Journal of the institute of brewing. vol. 111, No. 4.

Boivin, P. (2005). Emergent mycotoxins in malting barley. Proceeding of the Congress - European Brewery Convention. Fachverlag Hans Carl.

Brown I, Poggio L, Gimona A, Castellazzi M (2011) Climate change, drought risk and land capability for agriculture: implications for land use in Scotland. Reg Env Change 11:503-518

Cairns TC, Nai C, Meyer V. How a fungus shapes biotechnology: 100 years of Aspergillus niger research. Fungal 
Biol Biotechnol. 2018; 5:13. Published 2018 May 24. doi:10.1186/s40694-018-0054-5

Daniel Tadesse and Beyene Derso, 2019. The status and constraints of food barley production in the North Gondar highlands, North Western Ethiopia. Journal of Agric \& Food Security.

Dupire, S. (2003) Mycotoxins and other contaminants in the malting and brewing industries. European brewery convention congress, Proceedings, Dublin, Nurnberg, Germany: Fachverlag Hans Carl, CD ROM, Contribution 129

FAOSTAT. Food and Agriculture Organization of the United Nations. Available online: http://www.fao.org/ faostat/en/ (accessed on 28 March 2019).

Food and Drug Administration [FDA]. 2011. FDA mycotoxin regulatory guidance: a guide for grain elevators, feed manufacturers, grain processors, and exporters. National Grain and Feed Association, Washington, D. C.

Frisvad JC, Smedsgaard J, Larsen TO. and Samson RA. (2004) Mycotoxins, drugs and other extrolites produced by species in Penicillium subgenus Penicillium. Studies in Mycology, 49:201-242.

Getachew Agegnehu, Paul N. Nelson, Michael I. Bird. (2016) The effects of biochar, compost and their mixture and nitrogen fertilizer on yield and nitrogen use efficiency of barley grown on a Nitisol in the highlands of Ethiopia. Science of The Total Environment 569-570, pages 869-879.

Gonzalez M.L. Pereyra, C.A.R. Rosa, A.M. Dalcero and L.R. Cavaglieri(2011). Mycobiota and mycotoxins in malted barley and brewer's spent grain from Argentinean breweries. The society for applied biology. Letters in Applied Microbiology 53, 649-655.

Habtamu F., Kelbessa, U. and Funu (2001).Survey of Aflatoxin Contamination in Ethiopia. Ethiop J. Health Sci. $11(1): 17-25$..

EducardoA., Marianne B.2006. Work group report: Public health strategies for reducing aflatoxin exposure in developing countries. volume, 114.

International Agency for Research on Cancer (IARC) (2002). Some traditional herbal medicines, some mycotoxins, naphthalene and styrene. Monographs on the Evaluation of Carcinogenic Risks to Humans, 82, 21.

Karolina, B., Sylvie, B., Renata, M., \& Zdenek, S. (2011). Monitoring of selected aflatoxins in brewing materials and beer by liquid chromatography/mass spectrometry. Food Control, 25(2), 626-630.

María I. , Elena G., Elena and L. Adela L. 2010. Co-Occurrence ff Aflatoxins, Ochratoxin A and Zearalenone in Barley from Northern Region Of Spain. Journal of mycotoxins.

Melotte, L. (2004) Survey on the analysis of mycotoxins. Analysis Committee of the European Brewery Convention, European Brewery Association. JI Brewing 110, 235-239.

Purugganan, M.D.; Fuller, D.Q. The nature of selection during plant domestication. Nature 2009, 457, 843-848.

Rizzi L, Simioli M, Roncada P \& Zaghini A. (2003) Aflatoxin B1 and clinoptilolite in feed for laying hens. Effect on egg quality, mycotoxin residues in livers and hepatic mixed function oxidase activities. Journal of Food Protection, 66:860-865.

Robens JF and Richard JL 1992. Aflatoxins in animal and human health. Rev Environ Contam Toxicol. 1992;127:69-94

Summary of data reported and evaluation. IARC Monographs on the evaluation of the carcinogenic risk to humans,vol. 82. International Agency for Research on Cancer, Lyon, France.

Wendorf, F.; Schild, R.; El Hadidi, N.; Close, A.E.; Kobusiewicz, M.; Wieckowska, H.; Issawi, B.; Haas, H. Use of barley in the Egyptian late paleolithic. Science 1979, 205, 1341-1347. [CrossRef]

Wild C \& Gong Y. (2010) Mycotoxins and human disease: a largely ignored global health issue. Carcinogenesis, $31: 71-82$ 